\title{
FLUOR PADA RESTORASI GLASS IONOMER CEMENT DAN RESIN KOMPOSIT TERHADAP PERUBAHAN pH
}

Ratnasari Dyah P, Lies Elina P.

Jurusan Keperawatan Gigi Poltekkes Tanjungkarang

ratnasaridyah9@gmail.com/085366656833

lieselina@poltekkes-tjk.ac.id/087899548468

\begin{abstract}
Abstret
OF FLUOR IN GLASS IONOMER CEMENT RESTORATION AND COMPOSITE RESINS TO pH CHANGE
\end{abstract}

Aesthetically, a consideration in carrying out dental caries restoration. material which is often used as a restoration material is glass ionomer cement and composite resin, this restoration material is tooth-colored, has good strength and both contains fluorine and gives a good aesthetic. The purpose of this study is to see the effectiveness of fluoride content in both of these materials against changes in salivary $\mathrm{pH}$ in preventing secondary caries. This type of experimental research with the design of one group pretest-posttest design, sampling using a simple random sampling technique. The location of the study was 32 students in the fifth grade SDN Rajabasa Jaya, Bandar Lampung. It was concluded that the restoration using glass ionomer cement overlay material was more significant in influencing changes in salivary $\mathrm{pH}$ compared to composite resin material overlay, the release of fluorine in glass ionomer cement restoration was highest on the 7th day after restoration, decreasing the next day.

Keywords: salivary pH, ART

\section{Abstrak \\ FLUOR PADA RESTORASI GLASS IONOMER CEMENT DAN RESIN KOMPOSIT TERHADAP PERUBAHAN pH}

Estetik, menjadi pertimbangan dalam melakukan restorasi karies gigi. material yang sering digunakan sebagai bahan restorasi adalah glass ionomer cement dan resin komposit, bahan restorasi ini sewarna gigi, mempunyai kekuatan yang cukup baik dan keduanya mengandung fluor serta memberikan estetik yang baik. Tujuan penelitian melihat efektifitas kandungan fluor pada kedua bahan tersebut terhadap perubahan $\mathrm{pH}$ saliva dalam mencegah terjadinya sekunder karies. Jenis penelitian experimental dengan rancangan one group pretest-postest design, Pengambilan sampel mengunakan teknik simpel random sampling. Lokasi penelitian dilakukan di siswa siswi kelas V SDN Rajabasa Jaya, Bandar Lampung sebanyak 32 siswa. Disimpulkan bahwa restorasi mengunakan bahan tumpatan glass ionomer cement lebih signifikan dalam mempengaruhi perubahan $\mathrm{pH}$ saliva dibandingkan dengan bahan tumpatan resin komposit, pelepasan fluor pada restorasi glass ionomer cement tertinggi pada hari ke 7 setelah restorasi, semakin menurun pada hari hari berikutnya.

Kata kunci : pH saliva, ART

\section{Pendahuluan}

Karies gigi merupakan penyakit multifaktoral yang disebabkan oleh berbagai faktor, lima faktor utama penyebab karies adalah retensi plak, frekuensi asupan karbohidrat, asam, faktor $\mathrm{pH}$ asam saliva serta fluoride dan elemen-elemen lain yang dapat mengontrol perkembangan karies 
Karies gigi disebabkan hilang/larutnya ion - ion mineral secara kronis dan terus menerus dari permukaan enamel baik pada mahkota gigi, ataupun permukaan akar oleh aktivitas bakteri. Bakteri akan merubah glukosa dan karbohidrat pada makanan menjadi asam melalui proses fermentasi. Asam akan terus diproduksi oleh bakteri dan akhirnya merusak struktur gigi. Asam yang dihasilkan dari fermentasi gula oleh bakteri akan menyebabkan terjadinya demineralisasi lapisan enamel sehingga struktur gigi menjadi rapuh dan berlubang.

Proses demineralisasi dapat terjadi sebaliknya, jika $\mathrm{pH}$ saliva kembali netral. Produk-produk ion-ion mineral atau hidroksiapatit yang larut akan dikembalikan lagi ke gigi melalui proses remineralisasi, keadaan ini dapat diperkuat dengan adanya ion fluor. Pemberian fluor dapat menghentikan terjadinya demineralisasi dan meningkatkan remineralisasi karena ikatannya dengan kalsium dan fosfat pada saliva. fluoride bekerja melalui reaksi dengan hidroksiapatite yang menbentuk fluorapapatit yang lebih kuat dalam kondisi saliva yang asam.

Kondisi gigi yang sudah karies salah satu penanggulangannya yaitu dengan merestorasi/menumpat gigi yang mengalami karies dengan bahan restorasi. Teknologi produksi bahan restorasi saat ini berkembang cukup pesat, hal ini membuat pasien mempunyai banyak pilihan dalam memilih jenis material untuk merestorasi/ menambalkan gigi nya yang mengalami kerusakan gigi.

Masing-masing material memiliki kelebihan dan kekurangan baik dari sifat fisik dan mekanis, estetika serta cara manipulasi. Material restorasi gigi harus dipilih secara tepat dan cermat sesuai dengan indikasinya.

Salah satu material yang sering digunakan sebagai bahan restorasi adalah glass ionomer cement. Karena bahan ini dapat berikatan secara kimiawi dengan jaringan gigi, memiliki sifat yang cukup baik, memiliki daya rekat yang baik, warna cukup estetik, sederhana dalam mengaplikasikannya, dan mengandung fluor yang dapat menghambat laju perjalanan karies. Glass ionomer cement melepaskan ion fluor dalam jangka waktu yang cukup lama.

Pilihan lain yang digunakan dokter gigi adalah resin komposit, yang memiliki warna senada warna gigi, memenuhi unsur estetik, juga mengandung ion fluor.

Kedua pilihan material tersebut apakah dapat mempengaruhi $\mathrm{pH}$ saliva yang dapat mencegah terjadinya sekunder karies.

Tujuan penelitian ini melihat efektifitas fluor yang terkandung dalam glass ionomer cement dan composite resin terhadap perubahan $\mathrm{pH}$ saliva yang mempengaruhi proses remineralisasi, karena saliva memiliki kemampuan buffering yang bermanfaat dalam mencegah terjadinya sekunder karies.

\section{Metode}

Jenis penelitian yang digunakan pada penelitian ini yaituexperimental dengan rancangan one group pretest-postest design (Notoatmodjo, 2010).

Dalam rancangan ini digunakan satu kelompok subjek. Pertama-tama dilakukan pengukuran, lalu dikenakan perlakuan untuk kedua kalinya dengan rancangan sebagai berikut :

\section{DesainPenelitian}

\begin{tabular}{|c|c|c|}
\hline Pretest & Treatment & Posttest \\
\hline $\mathrm{O}_{1}$ & $\mathrm{X}$ & $\mathrm{O}_{2}$ \\
\hline
\end{tabular}


JURNAL KESEHATAN GIGI

(Dental Health Journal)

Vol. 8 No.1 Pebruari 2021

$\mathrm{Q}_{1} \quad$ : yaitu pretest, untuk mengetahui pH saliva sebelum dilakukan penum-patan dengan glass ionomer cement dan resinkomposit

$\mathrm{O}_{2} \quad$ : yaitu posttest, untuk Mengetahui $\mathrm{pH}$ saliva sesudah dilakukan penumpatan dengan glass ionomer cement dan resin komposit

O2.1 : pH sesudah 7 hari penumpatan

O2.2 : pH sesudah 14 hari penumpatan

O2.3 : pH sesudah 21 hari penumpatan

O2.4 : pH sesudah 28 hari penumpatan

$\mathrm{X}$ : Pemberian perlakuan penumpatan glass ionomer cement dan resin komposit dengan teknik ART

$\mathrm{X} 1$ : Restorasi dengan glass ionomer cemen

$\mathrm{X} 2$ : Restorasi dengan resin composit

Populasi dalam penelitian ini dilakukan total populasi. Analisis statistik yang dilakukan dalamp enelitian ini adalah penelitian univariat untuk mendiskripsikan tiap variabel. Jumlah sampel 30 siswa dilakukan pada siswa kelas $\mathrm{V}$ merupakan total populasi. Analisis statistic yang dilakukan dalam Penelitian ini adalah analisa univariate Bertujuan untuk mendeskripsikan tiap variable Penelitian adalah $\mathrm{pH}$ sebelum, $\mathrm{pH}$ sesudah 7 hari, 14 hari,21 hari, 28 hari sesudah restorasi glassionomer cement dan restorasi resin komposit

Analisis bivariate bertujuan untuk melihat efektifitas fluor yang terkandung dalam bahan tumpat Glass ionomer cement terhadap $\mathrm{pH}$ saliva dan restorasi resin composite terhadap $\mathrm{pH}$ saliva dengan anova. $\mathrm{pH}$ di ukur sesudah 7 hari, 14 hari, 21 hari dan 28 hari sesudah dilakukan tumpatan glass ionomer cemen dan composite resin.

\section{Hasil Peneitian}

Hasil penelitian di dapatkan sebagai berikut :

Tabel 1. pH Sebelum Restorasi/Penumpatan

\begin{tabular}{cccccc}
\hline & & \multicolumn{3}{c}{ Katagori pH sebelum } & \\
\cline { 3 - 5 } & & Asam & Netral & Basa & Total \\
\hline \multirow{2}{*}{ Bahan } & GI & 0 & 9 & 7 & 16 \\
& Resin & 1 & 10 & 5 & 16 \\
\hline \multicolumn{2}{c}{ Total } & 1 & 19 & 12 & 32 \\
\hline
\end{tabular}

Tabel 2. pH 7 Hari Setelah Restorasi/ Tumpatan

\begin{tabular}{ccccc}
\hline & & \multicolumn{2}{c}{ Kategori pH 7 hari } & \\
\cline { 3 - 4 } & & Netral & Basa & Total \\
\hline \multirow{2}{*}{ Bahan } & GI & 16 & 0 & 16 \\
& Resin & 13 & 3 & 16 \\
\hline \multicolumn{2}{c}{ Total } & 29 & 3 & 32 \\
\hline
\end{tabular}

Tabel 3. pH 14 Hari Setelah Restorasi/Tumpatan

\begin{tabular}{cccccc}
\hline & & \multicolumn{3}{c}{ Kategori pH 14 hari } & \\
\cline { 2 - 5 } & & Asam & Netral & Basa & Total \\
\hline \multirow{2}{*}{ Bahan } & GI & 1 & 13 & 2 & 16 \\
& Resin & 2 & 10 & 4 & 16 \\
\hline \multicolumn{2}{c}{ Total } & 3 & 23 & 6 & 32 \\
\hline
\end{tabular}

Tabel 4. pH 21 Hari Setelah Restorasi/Tumpatan

\begin{tabular}{cccccc}
\hline & & \multicolumn{3}{c}{ Kategori pH 21 hari } & \\
\cline { 2 - 5 } & & Asam & Netral & Basa & Total \\
\hline \multirow{2}{*}{ Bahan } & GI & 1 & 11 & 4 & 16 \\
& Resin & 2 & 9 & 5 & 16 \\
\hline Total & 3 & 20 & 9 & 32 \\
\hline
\end{tabular}

Tabel 5. pH 28 hari setelah Restorasi tumpatan

\begin{tabular}{cccccc}
\hline & & \multicolumn{3}{c}{ Kategori pH 28 hari } & \\
\cline { 2 - 5 } & & Asam & Netral & Basa & Total \\
\hline \multirow{2}{*}{ Bahan } & GI & 1 & 12 & 3 & 16 \\
& Resin & 1 & 10 & 5 & 16 \\
\hline \multicolumn{2}{c}{ Total } & 2 & 22 & 8 & 32 \\
\hline
\end{tabular}


JURNAL KESEHATAN GIGI

(Dental Health Journal)

Vol. 8 No.1 Pebruari 2021

Tabel 6. pH Restorasi Glass Ionomer Cement dan Restorasi Composire Resin

\begin{tabular}{|c|c|c|}
\hline \multicolumn{3}{|c|}{ Correlation Sig } \\
\hline $\begin{array}{l}\mathrm{pH} \text { GI sebelum \& } \\
\text { pH resin sebelum }\end{array}$ & .282 & .290 \\
\hline $\begin{array}{l}\text { pH GI } 7 \& \text { pH Resin } \\
7\end{array}$ & 000 & 000. \\
\hline $\begin{array}{l}\text { pH GI } 14 \& \text { pH } \\
\text { Resin } 14\end{array}$ & .213 & .429 \\
\hline $\begin{array}{l}\text { pH GI } 21 \& \text { pH } \\
\text { Resin } 21\end{array}$ & -.105 & .698 \\
\hline $\begin{array}{l}\text { pH GI } 28 \& \text { pH } \\
\text { Resin } 28\end{array}$ & .346 & .189 \\
\hline Variabel & Mean & $\mathrm{T}$ \\
\hline $\begin{array}{l}\text { pH GI sebelum - } \\
\text { pH Resin sebelum }\end{array}$ & .18750 & 1.145 \\
\hline pH GI7 - pH Resin 7 & -.18750 & -1.861 \\
\hline $\begin{array}{l}\text { pH GI } 14-\text { pH Resin } \\
14\end{array}$ & -.06250 & -.368 \\
\hline $\begin{array}{l}\text { pH GI } 21-\text { pH Resin } \\
21\end{array}$ & .00000 & .000 \\
\hline $\begin{array}{l}\text { pH GI } 28-\text { pH Resin } \\
28\end{array}$ & -.12500 & -.808 \\
\hline
\end{tabular}

Pengambilan keputusan :

1. T hasil uji t $\mathrm{pH}$ saliva sebelum tumpatan GI dan Resin di dapat hasil t hitung 1.145 dengan nilai probabilitas 0,282 , oleh karen nilai probabilitas $0,282>0,05$ maka Ho di terima yang berarti tidak ada perbedaan yang signifikan antara $\mathrm{pH}$ sebelum dilakukan tumpatan GI dan Resin dengan nilai mean 0,18750

2. $\mathrm{T}$ hasil uji $\mathrm{t} \mathrm{pH}$ saliva setelah 7 hari dilakukan tumpatan GI dan Resin di dapat hasil $t$ hitung $-0,1861$ dengan nilai probabilitas 0,000 oleh karen nilai probabilitas $0,000<0,05$ maka Ho di tolak yang berarti ada perbedaan yang signifikan antara $\mathrm{pH}$ sebelum dilakukan tumpatan GI dan Resin mean -0,18750
3. $\mathrm{T}$ hasil uji $\mathrm{t} \mathrm{pH}$ saliva setelah 14 hari dilakukan tumpatan GI dan Resin di dapat hasil $\mathrm{t}$ hitung $-0,368$ dengan nilai probabilitas 0,213 oleh karen nilai probabilitas $0,213>0,05$ maka Ho di terima yang berarti tidak ada perbedaan yang signifikan antara $\mathrm{pH}$ sebelum dilakukan tumpatan GI dan Resin mean 0,06250

4. $\mathrm{T}$ hasil uji $\mathrm{t} \mathrm{pH}$ saliva setelah 21 hari dilakukan tumpatan GI dan Resin di dapat hasil $\mathrm{t}$ hitung $-0,368$ dengan nilai probabilitas 0,105 oleh karen nilai probabilitas 0,1053 > 0,05 maka Ho di terima yang berarti tidak ada perbedaan yang signifikan antara $\mathrm{pH}$ sebelum dilakukan tumpatan GI dan Resin mean 0,00000

5. $\mathrm{T}$ hasil uji t $\mathrm{pH}$ saliva setelah 28 hari dilakukan tumpatan GI dan Resin di dapat hasil $\mathrm{t}$ hitung $-0,808$ dengan nilai probabilitas 0,105 oleh karena nilai probabilitas $0,346>0,05$ maka $\mathrm{Ho}$ diterima yang berarti tidak ada perbedaan yang signifikan antara $\mathrm{pH}$ sebelum dilakukan tumpatan GI dan Resin mean 0,12500

\section{Pembahasan}

Dari hasil penelitian diatas baik tumpatan Glass Ionomer cemen dan Composite resin menunjukkan perubahan $\mathrm{pH}$ saliva setelah hari ke 7 setelah restorasi.perubahan $\mathrm{pH}$ saliva terus terjadi pada hari ke 14, 21 dan hari ke 28 setelah restorasi, namun perubahan yang signifikan terjadi pada hari ke 7 . Hari ke $14,21.28$ perubahan $\mathrm{pH}$ tidak terlihat secara signifikan pada ke dua bahan restorasi.

Dari penjabaran di atas menunjukkan hasil bahwa sampel dengan $\mathrm{pH}$ netral jumlahnya semakin menurun, namun terlihat adanya kenaikan lagi pada restorasi hari ke 28. Terlihat pada restorasi glass ionomer 


\section{JURNAL KESEHATAN GIGI \\ (Dental Health Journal) \\ Vol. 8 No.1 Pebruari 2021}

cement dan restorasi komposite resin, namun pada restorasi glass ionomer cemet menunjukkan perubahan $\mathrm{pH}$ menjadi $\mathrm{pH}$ netral lebih banyak dari restorasi composit resin

Berdasarkan pendapat dari Davidson ada 2 mekanisme pelepasan fluor, yaitu pelepasan reaksi jangka pendek dan jangka panjang. Reaksi jangka pendek berkaitan dengan reaksi awal karena proses maturasi setelah setting time terjadi pelepasan fluor tertinggi pada 24 - 48 jam pertama setelah terpapar fluor. Kemudian menurun secara konstan setelah beberapa minggu atau beberapa bulan. Pada reaksi jangka panjang pelepasan fluor lebih rendah dan stabil sesuai dengan keseimbangan proses difusi.

$\mathrm{pH}$ saliva akan mempengaruhi mekanisme terjadinya karies berhubungan dengan proses demineralisasi dan remineralisasi, denagn Pemberian fluor dapat membantu menghentikan terjadinya demineralisasi. meningkatkan remineralisasi karena ikatannya dengan kalsium serta fosfat pada saliva. Fluoride bekerja dengan tiga cara, yaitu memperlambat proses karies gigi dengan menghambat terjadinya demineralisasi, meningkatkan resistensi email terhadap serangan asam, serta meningkatkan remineralisasi melalui reaksi dengan hidroksiapatit yang membentuk fluorapatit.

Unsur fluor dari restorasi Glass Ionomer dan composite resin akan diserap email. Adanya asupan fluor pada email efektif menghambat terjadinya proses deminaralisasi email. Terserapnya fluor tersebut mengakibatkan berkurangnya luas dinding karies pada artifisial disekeliling restorasi. Secara mekanisme fisika-kimia, fluor yang diserap email tersebut akan menghambat demineralisasi.

Gugus $\mathrm{OH}$ dalam kristal hidroksiapatite struktur gigi dapat disubstitusi oleh fluor berikatan dengan kalsium dan fosfat pada saliva menjadi fluoapatit yang lebih tahan terhadap pelarutan asam dipermukaan gigi, sehinggan terjadi proses remineralisasi. Reaksi remineralisasi ini sangat diperkuat oleh adanya keberadaan fluor. Dengan terjadinya proses remineralisasi menjadikan $\mathrm{pH}$ saliva menjadi netral, sehingga mencegah terjadinya secunder karies.

\section{Simpulan}

Dari penelitin yang dilakukan Restorasi mengunakan bahan tumpatan glass ionomer cement lebih signifikan dalam mempengaruhi perubahan $\mathrm{pH}$ saliva dibandingkan dengan bahan tumpatan resin komposit.

\section{Daftar Pustaka}

Be Kien Nio, 1987, Preventive Dentistry, Bandung, Yayasan Kesehatan Gigi, Indonesia

E. Ellis Pamela, Philip E. Benson. Potensial Hazard of Orthodonthic Treatment- What Your Patient Should Know. Sheffield : Journal of dental update, 2002;29:492-96

Darby ML, Walsh MM. Dental hygiene theory and practice (3rded). Canada: Saunders Elsevier, 2010; p.281-39. -----tentang debris indeks

Djuita, Iendah.1992.Spesifik Protection. Jakarta: Depkes RI

Herijulianti, E.I. Tari S. 2002. Pendidikan Kesehatan Gigi, Jakartas, EGC

Klumper GT. Hiser DG, Ravents MK. Efficacy Of Wax Containing Benzocaine In The Reilief Of Oral Mucosal Pain Caused By Orthodontic Appliances. USA. Am Journal Orthodonti Dentofacial Orthop, 2002; 122(4) :359-65. (Abstrak).

Megananda Hiranya Putri, dkk. 2012, Ilmu Pencegahan Penyakit Jaringan Keras dan Jaringan Pendukung Gigi, Jakarta: EGC 
Mokhtar M, 1998. Dasar - dasar Orthodonti ; Pertumbuhan dan Perkembangan Kraniodentofasial. Jakarata. IDI

Notoadmojo, Soekidjo. 2010. Metodologi Penelitian Kesehatan. Rineka Cipta. Jakarta

Rahilly G, Price N. Current Products and practice Nickel Allergy And Orthodontics. Journal Of Orthodontik, 2003;30: 171-4.

Robert Ireland . 2006. Clinical textbook of dental hygiene \& therapy. Australia: Blackwell Munksgaard, a Blackwell Publishing Company.

Sugiyono. 2011, Metode Penelitian Kuantitatif, Kualitatif dan R \& D, Bandung: Alfabeta

Suharsimi Arikunto, 2010, Prosedur Penelitian Suatu Pendekatan Praktik ,Jakarta: Rineka Cipta

Megananda dkk.2012 .Ilmu Pencegahan Penyakit Jaringan Keras dan Jaringan Pendukung Gigi. Jakarta: EGC

Notoatmodjo,Soekidjo.2010.Metodologi Penelitian Kesehatan. Jakarta: Rineka Cipta

Riskesdas 2013. Kesehatan Gigi dan Mulut.

Tarigan, Rasinta.1994.Kesehatan Gigi dan Mulut. Jakarta: EGC 